\title{
Modeling rennet coagulation time and curd firmness of milk
}

\author{
G. Bittante ${ }^{1}$ \\ Department of Animal Science, University of Padova (Padua), Viale dell'Università 16, 35020 Legnaro (PD), Italy
}

\begin{abstract}
Milk coagulation properties (MCP) are traditionally expressed using rennet coagulation time (RCT), time to curd firmness $(\mathrm{CF})$ of $20 \mathrm{~mm}\left(\mathrm{k}_{20}\right)$, and $\mathrm{CF} 30 \mathrm{~min}$ after enzyme addition $\left(\mathrm{a}_{30}\right)$ values, all of which are single-point measures taken from the output of computerized renneting meters, such as the Formagraph. Thus, traditional MCP use only some of the available information. Moreover, because of the worldwide spreading of breeds such as the Holstein-Friesian, characterized by late-coagulating milk, it happens often that some samples do not coagulate at all, that $\mathrm{a}_{30}$ is strongly and negatively related to RCT, and that $\mathrm{k}_{20}$ is not measurable. The aim of the present work was to model $\mathrm{CF}$ as a function of time $\left(\mathrm{CF}_{\mathrm{t}}, \mathrm{mm}\right)$ over a 30 min interval. The model tested was $C F_{t}=C F_{P} \times\left(1-e^{-k_{C F} \times(t-R C T)}\right)$, where $C F_{P}(\mathrm{~mm})$ is the potential asymptotical $\mathrm{CF}$ at an infinite time, $k_{C F}$ $\left(\min ^{-1}\right)$ is the curd firming rate constant, and RCT is measured in minutes. The $\mathrm{CF}_{\mathrm{t}}$ model was initially applied to data of milk of each of 105 Brown Swiss cows from 7 herds, each sampled once (trial 1). Four samples did not coagulate within $30 \mathrm{~min}$. Eighty-seven of the 101 individual equations obtained fit the $\mathrm{CF}$ data of milk samples very well, even though the samples differed in composition, and were produced by cows of different ages and days in milk, reared on different farms (coefficient of determination $>0.99$; average residual standard deviation $=0.21 \mathrm{~mm}$ ). Samples with a very late RCT (slowly coagulating samples) yielded so few observational data points that curve parameters could not be precisely estimated. The repeatability of $\mathrm{CF}_{\mathrm{t}}$ equation parameters was estimated using data obtained from 5 replicates of each of 2 samples of bulk milk from 5 Holstein-Friesian cows analyzed every day for 5 consecutive days (trial 2). Repeatability of RCT was better than that of the other 2 parameters. Moreover, traditional MCP values $\left(\mathrm{RCT}, \mathrm{a}_{30}\right.$, and $\mathrm{k}_{20}$ ) can be obtained from the individual $\mathrm{CF}_{\mathrm{t}}$ equations, using
\end{abstract}

Received May 6, 2011.

Accepted June 28, 2011.

${ }^{1}$ Corresponding author: giovanni.bittante@unipd.it all available information. The MCP estimated from equations were very similar to the single-point measures yielded by the computerized renneting meter (coefficient of determination $>0.97$ ), but repeatability was slightly better. The model allowed the estimation of $k_{20}$ for samples with a very late coagulation or with very slow curd firming. Finally, the 3 novel parameters used to assess different milk samples were less interdependent than are the traditional measures, and their practical and scientific utility requires further study.

Key words: rennet coagulation time, curd firmness, modeling, cheese making

\section{INTRODUCTION}

Milk coagulation properties (MCP) receive much attention in dairy science and industry, mainly because the amount of milk used to manufacture cheese is growing worldwide, and several works have confirmed the importance of MCP in terms of cheese processing, yield, and quality (Bynum and Olson, 1982; Aleandri et al., 1989; Martin et al., 1997; Wedholm et al., 2006; De Marchi et al., 2008).

Several techniques can be used to study MCP (Klandar et al., 2007). The most common approach, both at the research and industry levels, is to monitor the viscosity of milk samples, maintained at a fixed temperature, following addition of rennet. The Formagraph (from the Italian word formaggio, cheese; Foss Electric A/S, Hillerød, Denmark) apparatus has been customized to evaluate several milk samples at the same time and has been widely used for some decades (Annibaldi et al., 1977; Zannoni and Annibaldi, 1981; McMahon and Brown, 1982; Okigbo et al., 1985).

The means by which the Formagraph measures coagulation is based upon movement of small loop pendulums (made of stainless steel) that are immersed in linearly oscillating samples of coagulating milk. Minute forces, registered by the device, are applied to the pendulums as a consequence of gel formation in the moving milk sample (McMahon and Brown, 1982). A typical diagram of firmness versus time is shown in Figure 1. Years ago, each output was charted on photographic paper and measurements were performed manually; today, the process is computerized. Three parameters are 


\section{ENZYME ADDITION}

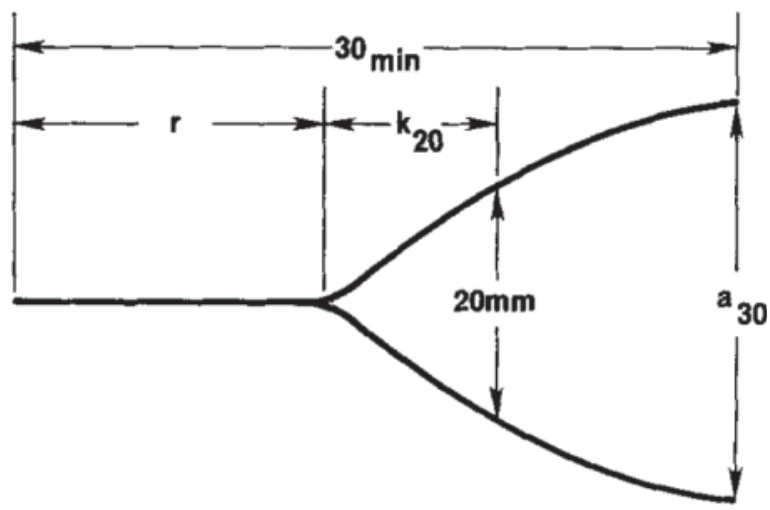

Figure 1. Diagram of rennet coagulation time $(\mathrm{r}=\mathrm{RCT}, \mathrm{min})$ and curd firmness traits [time to curd firmness of $20 \mathrm{~mm}\left(\mathrm{k}_{20}\right)$, min, and curd firmness 30 min after enzyme addition $\left.\left(\mathrm{a}_{30}\right), \mathrm{mm}\right]$ as a function of time as recorded with the Formagraph (Foss Electric A/S, Hillerød, Denmark; from McMahon and Brown, 1982).

usually determined: (1) rennet coagulation time (RCT, min), obtained by measuring the distance from the origin (the time of addition of rennet to milk) to the point where the baseline begins to increase in width; (2) time to curd firmness $(\mathbf{C F})$ of $20 \mathrm{~mm}\left(\mathbf{k}_{\mathbf{2 0}}\right.$, min), which is the interval from the start of gel development (RCT) until an oscillation width of $20 \mathrm{~mm}$ is attained; and, (3) CF 30 min after enzyme addition $\left(\mathbf{a}_{\mathbf{3 0}}, \mathbf{m m}\right)$, which is the width of the graph when the test usually ends.

Technical evolution of the Formagraph, and the computerized renneting meters (CRM) now available, have maintained the principle of the testing procedure but measurements are now performed automatically and the results continuously recorded in computer memory, but the data are treated to yield the traditional outputs, even if in the meantime several studies have been published on modeling of dynamics of milk curdling using different rheometers (Douillard, 1973, 1986; Gervais and Cerf, 1983; McMahon et al., 1984; Dejmek, 1987; O'Callaghan and Guinee, 1996). Recently, near-infrared reflectance spectroscopy (NIRS) and other optical methods have been employed to monitor coagulation (O'Callaghan et al., 2002; Kübarsepp et al., 2005a; Fagan et al., 2007); the optical values were transformed to simulate the traditional parameters. Moreover, such parameters can also be indirectly predicted by mediuminfrared reflectance spectroscopy (MIRS) of fresh milk, without the need to induce coagulation, employing appropriate calibration algorithms (Dal Zotto et al., 2008; De Marchi et al., 2009).

The major limitations of the traditional MCP are (1) the existence of noncoagulating samples, (2) problems in acquiring $\mathrm{k}_{20}$ values and their repeatability, and (3) the nature of the information yielded by $a_{30}$ values.
The first problem in traditional MCP assessment is that, sometimes, coagulation is not noted during the 30-min test interval (milk showing this trait is termed noncoagulating; Ikonen et al., 2004; Tyrisevä et al., 2004). In such an instance, it is obviously impossible to estimate $\mathrm{RCT}, \mathrm{k}_{20}$, or $\mathrm{a}_{30}$. This problem is of growing importance because the Holstein-Friesian has become the leading breed worldwide and yields noncoagulating milk much more frequently than is the case with other dairy breeds, some Scandinavian breeds excluded (Ikonen et al., 1999; De Marchi et al., 2007). It is important to document the frequency of noncoagulating milk samples, for both industrial and scientific purposes, but this creates certain statistical problems in terms of correct evaluation of data from coagulating samples (Cecchinato and Carnier, 2011; Cecchinato et al., 2011). Further, $\mathrm{k}_{20}$ cannot be estimated for coagulating samples with long RCT, in which curd firming does not permit attainment of an oscillation interval of $20 \mathrm{~mm}$ within $30 \mathrm{~min}$. The rise in frequency of slowly coagulating milk samples renders the $\mathrm{k}_{20}$ trait of decreasing utility. Moreover, $\mathrm{k}_{20}$ values are characterized by lower repeatability and reproducibility than is the case with RCT and have often been excluded from research evaluations, despite its practical importance (it is considered an indicator of the optimal time for curd cutting). Lastly, the $\mathrm{a}_{30}$ value is often highly dependent on RCT, both phenotypically and genetically (Ikonen et al., 1999, 2004; Cassandro et al., 2008; Cecchinato et al., 2011). It is evident that the longer the time to coagulation, the shorter will be the interval available for curd firming and the lower the final firmness that can be achieved. Any informative value of $\mathrm{a}_{30}$ over and above that afforded by RCT is, thus, very limited, both phenotypically and genetically, especially when milk from late-coagulating breeds is studied.

To overcome these limitations, new technologies and the use of more information afforded by traditional analysis must be explored. The most recent instruments store, and give ready access to, information obtained at any time during coagulation. Hence, the objective of the present work was to exploit all available information by appropriately modeling the curd-firming process over time $\left(\mathbf{C F}_{\mathrm{t}}\right)$ using data measured by CRM. New parameters relevant to coagulation properties are explored, with the aim of summarizing all available information to yield more informative parameters respect to the traditional MCP traits.

\section{MATERIALS AND METHODS}

To test $\mathrm{CF}_{\mathrm{t}}$ modeling of cow milk, 2 experimental data sets were used. 


\section{Trial 1: Evaluation of Model Fit}

The first database consisted of information from 105 Brown Swiss cows reared in 7 herds within the province of Trento (Italy). Fifteen cows from each herd were individually sampled once during afternoon milking (on a single sampling date for each herd). All samples, devoid of preservative, were refrigerated and transported to the Cheese-Making Laboratory of the Department of Animal Science of the University of Padova (Legnaro, Italy) and analyzed the following morning in terms of chemical composition and MCP.

\section{Trial 2: Repeatability of Equation Parameters and MCP Data}

The second data set was obtained by collecting and mixing milk produced during a Monday morning milking of 5 Holstein-Friesian cows reared in the Experimental Farm of the College of Agriculture of the University of Padova (Legnaro, Italy). The bulk milk, after gentle mixing, was aliquoted into 10 bottles and refrigerated at $6^{\circ} \mathrm{C}$ at the Cheese-Making Laboratory. On each of 5 mornings, from Monday to Friday, the milk of 2 bottles, after gentle mixing, was analyzed in terms of chemical composition and MCP and 5 replicates from each bottle were employed to yield 50 observations in total.

\section{Chemical Analyses and CF Measurements}

All samples were analyzed for fat, protein, lactose, and casein levels, and for titratable acidity, expressed in Soxhlet-Henkel degrees (Foss FT 120 FC; Foss Elec$\operatorname{tric} \mathrm{A} / \mathrm{S})$.

Milk coagulation properties were determined using a Formagraph. Milk samples $(10 \mathrm{~mL})$ were heated to $35^{\circ} \mathrm{C}$, and $200 \mu \mathrm{L}$ of a rennet solution (Hansen standard 160 with $80 \pm 5 \%$ chymosin and $20 \pm 5 \%$ pepsin; $\mathrm{Pa}-$ covis Amrein AG, Bern, Switzerland) diluted to 1.6\% in distilled water, was added to the milk. Curd firmness was evaluated over the next $30 \mathrm{~min}$. This afforded direct measurements of traditional MCP parameters: $\mathrm{RCT}, \mathrm{k}_{20}$, and $\mathrm{a}_{30}$. Files containing $120 \mathrm{CF}$ values for each replicate, as recorded every $15 \mathrm{~s}$, were retrieved.

Four samples from trial 1 did not coagulate within $30 \mathrm{~min}$ and were classified as noncoagulating. These samples were excluded from analysis. One file from trial 2 was lost. The 101 coagulating individual samples of trial 1 were classified into 3 groups in terms of measured RCT: fast-coagulating samples (RCT $<17 \mathrm{~min}$ ), samples coagulating at an average rate $(17 \mathrm{~min} \leq \mathrm{RCT}$ $<22 \mathrm{~min}$ ), and slowly coagulating samples (RCT $\geq 22$ $\min )$.

\section{Description of the Model}

Usually, CF after coagulation rises continuously to the 30-min time point. The basic model adopted has some similarity, even if measured differently, to that of Douillard $(1973,1986)$ and was chosen to combine the following criteria: (a) an ability to fit $\mathrm{CF}_{\mathrm{t}}$ data obtained from milk samples of different cows in various contexts, (b) a small number of parameters, and (c) the possibility of interpreting model parameters as technological properties of the sample. The basic model tested was

$$
C F_{t}=C F_{P} \times\left(1-e^{-k_{C F} \times(t-R C T)}\right),
$$

where $C F_{t}$ is $\mathrm{CF}$ at time $t(\mathrm{~mm}) ; C F_{P}$ is the asymptotical potential value of $\mathrm{CF}$ at an infinite time $(\mathrm{mm}) ; k_{C F}$ is the curd-firming rate constant $\left(\mathrm{min}^{-1}\right)$; and $\mathrm{RCT}$ is measured in minutes.

This model uses all information available for estimation of the 3 parameters, which are not single-point measurements (unlike the traditional MCP). The parameter $C F_{P}$ is conceptually independent from test duration and is not intrinsically dependent on RCT (unlike $\mathrm{a}_{30}$ ). The parameter $k_{C F}$ describes the shape of the curve from the time of coagulation to infinity and is conceptually different from $\mathrm{k}_{20}$, as it is independent from $C F_{P}$, but (again) uses all available information. Lastly, the parameter $R C T$ is indeed the traditional measure, but is now estimated using all available data. Moreover, when an equation is obtained from data of a milk sample, it is easy also to compute the other traditional parameters $\mathrm{k}_{20}$ and $\mathrm{a}_{30}$, but, again, using all available information.

\section{Statistical Analyses}

Curvilinear regressions were fit to the $120 \mathrm{CF}_{t}$ observations available for each sample and were analyzed using the nonlinear procedure (PROC NLIN) of the SAS (SAS Institute, 2001). The parameters of each individual equation were estimated employing the Marquardt iterative method (350 iterations and $10^{-5}$ level of convergence). The performance of individual models was evaluated on the basis of convergence and by estimating standard error of the equation parameters, the coefficient of determination, and the residual standard deviation (RSD).

Means and standard deviation (by group) of individual parameter estimates, of the corresponding standard error values, and of the RSD of the 101 individual equations of trial 1 were also calculated. Means and standard deviation by group were also derived for RCT, 
$\mathrm{a}_{30}$, and $\mathrm{k}_{20}$, both traditionally measured and estimated by $\mathrm{CF}_{\mathrm{t}}$ modeling, as were their differences. Linear regression between measured and estimated values of $\mathrm{RCT}, \mathrm{a}_{30}$, and $\mathrm{k}_{20}$, was also performed.

The parameter estimates, the corresponding standard errors, and the RSD of the 49 equations obtained from the replicate analysis of bulk milk in trial 2, and also the measured and estimated RCT, $\mathrm{a}_{30}$, and $\mathrm{k}_{20}$ values were analyzed by ANOVA with inclusion of the day of analysis ( 5 levels, from Monday to Friday, 4 df), and within-day samples ( 2 samples per day, $5 \mathrm{df})$. The effect of day was tested on the variance of sample, and the effect of sample on residual variance.

The repeatability $(R T)$ of each equation parameter; of measured and estimated RCT, $\mathrm{a}_{30}$, and $\mathrm{k}_{20}$ values; and of milk composition traits was calculated as the value below which the absolute difference between 2 single observations, obtained by repeat analysis of the same milk sample under the same conditions and within a short period, was expected to lie, at a probability of $95 \%$, according to ISO (1994a,b):

$$
R T=2 \times\left(2 \sigma_{e}^{2}\right)^{0.5}
$$

\section{RESULTS}

\section{Trial 1: Evaluation of Fit of CF Equations}

The data reported in Table 1 show that the milk was of good-to-average quality (especially in terms of protein, CN, and acidity levels), and that the milk samples produced by Brown Swiss cows, analyzed in trial 1, were very variable in terms of the properties measured.

The Formagraph data showed that milk samples from 4 cows did not coagulate within the conventional 30min trial duration (these were, thus, termed noncoagulating samples); the $120 \mathrm{CF}_{\mathrm{t}}$ point observations on each coagulating sample were used to estimate individual
$\mathrm{CF}_{\mathrm{t}}$ equations. It was possible to write equations for all coagulating samples, although only 90 samples met the convergence criterion, and 11 did not (Table 2). The latter samples were all in the group of the slowly coagulating samples and the number of point observations after $\mathrm{RCT}$, and average $\mathrm{CF}_{\mathrm{t}}$ values, were both low. Moreover, the curve shape after RCT was rather straight. The $C F_{p}$ values calculated for samples with nonconvergent equations were very high $(>200 \mathrm{~mm})$; the standard error of the estimates were also elevated; and the $k_{C F}$ values were very low $\left(<1 \% \mathrm{~min}^{-1}\right)$, being also associated with high standard errors. However, curve fitting within the $30 \mathrm{~min}$ of the test was nonetheless very good $\left(\mathrm{R}^{2}>0.99\right.$ for all equations), and RSD were very low ( $<0.1 \mathrm{~mm}$ in 10 of the 11 samples). The $\mathrm{RCT}$ and $\mathrm{a}_{30}$ values estimated from individual nonconvergent equations were very similar to those measured directly by the Formagraph on the same samples, and were retained for further analysis; in only 1 sample with nonconvergent equations was $\mathrm{a}_{30}$ higher than $20 \mathrm{~mm}$, so that the $\mathrm{k}_{20}$ value, both measured and estimated, was available. In the other 10 instances, use of the individual equations rendered it possible to estimate $\mathrm{k}_{20}$ values, with reasonable accuracy, even if the sum of $\mathrm{RCT}$ and $\mathrm{k}_{20}$ was $>30$ min.

Moreover, 3 samples (all slowly coagulating) that met the convergence criterion had $C F_{p}$ values $>100 \mathrm{~mm}$ and $k_{C F}$ values $<3 \% \mathrm{~min}^{-1}$; these were considered to be outliers and were excluded from further analysis of the parameters mentioned. However, the estimated RCT and $\mathrm{a}_{30}$ values were similar to the measured values and also, in 2 instances, the $\mathrm{a}_{30}$ values were greater than 20 $\mathrm{mm}$, so that $\mathrm{k}_{20}$ values could be calculated and in the third case, extrapolated from the equation.

In total, 87 equations were retained from 101 coagulating samples (86\%), including all samples coagulating at fast and average rates. The fits of individual equations were very good; each coefficient of determination value was over 0.999 with an RSD under $0.7 \mathrm{~mm}$.

Table 1. Chemical composition and repeatability (RP) of the milk samples used for milk coagulation properties (MCP) analysis

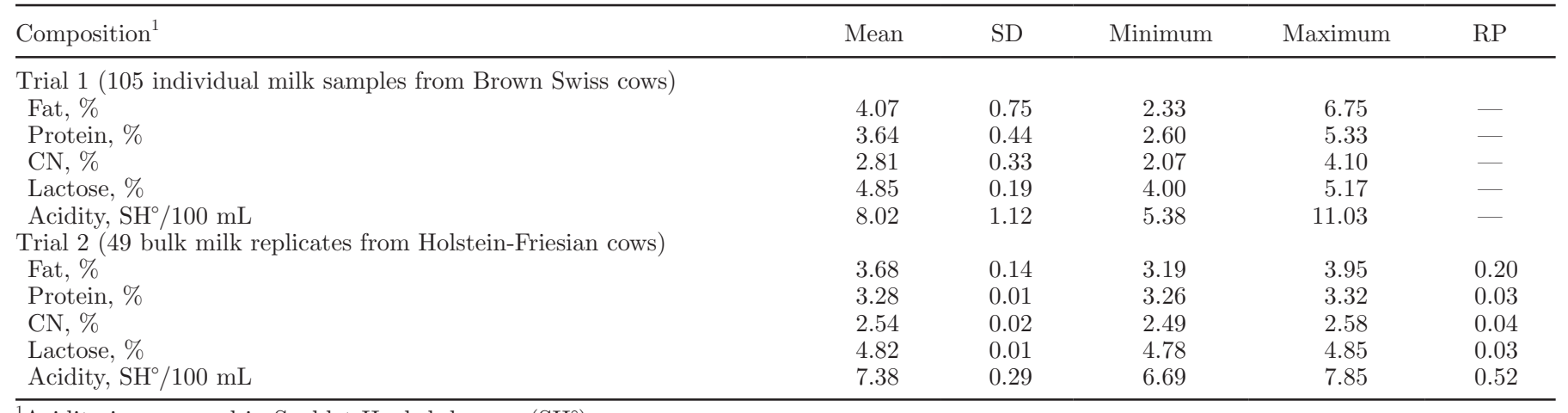

${ }^{1}$ Acidity is expressed in Soxhlet-Henkel degrees $\left(\mathrm{SH}^{\circ}\right)$. 
Table 2. Estimation of parameters of the curd firmness at time $t\left(C F_{t}\right)$ equations (trial 1: individual coagulating samples)

\begin{tabular}{|c|c|c|c|c|}
\hline \multirow[b]{2}{*}{ Parameter } & \multicolumn{3}{|c|}{ Coagulation time } & \multirow{2}{*}{$\begin{array}{c}\text { All } \\
\text { samples }\end{array}$} \\
\hline & Fast & Average & Slow & \\
\hline Samples, n & 30 & 52 & 19 & 101 \\
\hline \multicolumn{5}{|l|}{ Equation } \\
\hline Convergent, $\mathrm{n}$ & 30 & 52 & 8 & 90 \\
\hline Residual standard deviation (RSD), $\mathrm{mm}$ & 0.35 & 0.17 & $0.08^{1}$ & 0.21 \\
\hline \multicolumn{5}{|l|}{ Rennet coagulation time (RCT) } \\
\hline Estimates, n & 30 & 52 & 19 & 101 \\
\hline Average SE of estimates, min & 0.02 & 0.02 & 0.02 & 0.02 \\
\hline Average, $\min$ & 14.4 & 19.5 & 24.9 & 19.0 \\
\hline $\mathrm{SD}, \min$ & 1.7 & 1.6 & 2.1 & 4.0 \\
\hline \multicolumn{5}{|l|}{ Potential asymptotical curd firmness $\left(\mathrm{CF}_{\mathrm{P}}\right)$} \\
\hline Estimates, $\mathrm{n}$ & 30 & 52 & $5^{2}$ & 87 \\
\hline Average SE of estimates, mm & 0.17 & 0.87 & 2.85 & 0.75 \\
\hline Average, $\mathrm{mm}$ & 39.4 & 44.7 & 57.7 & 43.6 \\
\hline $\mathrm{SD}, \mathrm{mm}$ & 7.1 & 12.6 & 11.2 & 11.6 \\
\hline \multicolumn{5}{|l|}{ Curd-firming rate constant $\left(\mathrm{k}_{\mathrm{CF}}\right)$} \\
\hline Estimates, $\mathrm{n}$ & 30 & 52 & $5^{2}$ & 87 \\
\hline Average SE of estimates, $\% \times \min ^{-1}$ & 0.28 & 0.25 & 0.37 & 0.27 \\
\hline Average, $\% \times \min ^{-1}$ & 20.2 & 10.9 & 5.7 & 13.8 \\
\hline $\mathrm{SD}, \% \times \min ^{-1}$ & 5.6 & 3.5 & 1.6 & 6.4 \\
\hline
\end{tabular}

The average RCT value of the 101 coagulating samples was $19.0 \pm 4.0 \mathrm{~min}(\mathrm{CV}=21 \%)$; large differences were apparent among the 3 groups of fast-, normally, and slowly coagulating samples, as expected (Table 2). It is interesting to note that the average standard errors of RCT estimates were very low for all groups, being $0.02 \mathrm{~min}(0.1 \%$ of the mean value of the RCT).

The asymptotic parameter $C F_{P}$ of the 87 retained individual equations, which represents the maximum potential $\mathrm{CF}$ of a given sample after infinite time, averaged $43.6 \pm 11.6 \mathrm{~mm}$. The coefficient of variation was $26.6 \%$. Table 2 shows that this parameter tended to be higher in samples of slowly coagulating (compared with fast-coagulating) milk (57.7 \pm 11.2 vs. $39.4 \pm 7.1 \mathrm{~mm})$; this trend is the opposite of that usually found for $\mathrm{a}_{30}$. This confirms that the low $\mathrm{a}_{30}$ of slowly coagulating samples is simply an effect of the short time available for the curd firming process and that this parameter does not represent a correct measure of $\mathrm{CF}$ potential. The average standard error of the $87 C F_{P}$ estimates was low $(0.75 \mathrm{~mm} ; 1.7 \%$ of the mean $)$ and was better for fast- compared with slowly coagulating samples $(0.17$ vs. $2.85 \mathrm{~mm})$.

The $k_{C F}$ parameter, which measures the relative velocity of curd firming, was, on average, $13.8 \pm 6.4 \% \mathrm{~min}^{-1}$. The average $k_{C F}$ was greatly affected by RCT. Indeed, $k_{C F}$ varied from about $20 \% \mathrm{~min}^{-1}$ for fast-coagulating samples to $10 \% \mathrm{~min}^{-1}$ for samples showing an average coagulation rate, to $5 \% \mathrm{~min}^{-1}$ for slowly coagulating samples. The coefficient of variation of this parameter was very high (46.4\%), but the average standard error $\left(0.27 \% \mathrm{~min}^{-1} ; 1.9 \%\right.$ of the mean $)$ was still low and tended to be similar within the 3 sample groups (Table $2)$.

Table 3 compares the values of the usual MCP traits (RCT, $\mathrm{a}_{30}$, and $\mathrm{k}_{20}$ ) measured directly by the Formagraph in the traditional manner (single-point measures), or estimated using the $C F_{t}$ equations obtained individually for each milk sample. On average, the estimated RCT values were slightly longer (by $0.3 \mathrm{~min}$ ) than were the measured values, especially for fast-coagulating milk (0.6 min). In each instance, the variability of the difference between measured and estimated RCT was very low (the SD was $0.4 \mathrm{~min}$; equal to $2.1 \%$ of the mean). Notably, the Formagraph smoothes curves by taking a mobile average of $C F_{t}$ data; this explains the curvilinear graph shape both before and after coagulation (no singular point, or cusp, is detectable), as can be noted from Figure 2. It is likely that such smoothing renders the definition of RCT by the Formagraph as the time from addition of rennet to the first observation with a $C F_{t}>1 \mathrm{~mm}$, thus not with a $C F_{t}>0 \mathrm{~mm}$, as estimated using the $C F_{t}$ equation.

The average difference between the $2 \mathrm{a}_{30}$ measurements was also very low $(0.2 \mathrm{~mm} ; 0.7 \%$ of the mean value), although the difference varied between -0.6 $\mathrm{mm}$ for fast-coagulating samples to $+1.2 \mathrm{~mm}$ for those that coagulated slowly. The variability of the difference for this trait was slightly higher (the SD was $0.8 \mathrm{~mm}$; $2.8 \%$ of the mean) than was the case for RCT. 
Table 3. Comparison between milk coagulation properties (MCP) measured by a Formagraph ${ }^{1}$ or estimated by curd firmness at time $t\left(C F_{t}\right)$ equations (trial 1: individual coagulating samples)

\begin{tabular}{|c|c|c|c|c|}
\hline \multirow[b]{2}{*}{ Item $^{2}$} & \multicolumn{3}{|c|}{ Coagulation time } & \multirow{2}{*}{$\begin{array}{c}\text { All } \\
\text { samples }\end{array}$} \\
\hline & Fast & Average & Slow & \\
\hline \multicolumn{5}{|c|}{ Rennet coagulation time (RCT), min } \\
\hline Observations, $\mathrm{n}$ & 30 & 52 & 19 & 101 \\
\hline Measured (M) & 13.8 & 19.2 & 24.9 & 18.7 \\
\hline Estimated (E) & 14.4 & 19.5 & 24.9 & 19.0 \\
\hline $\mathrm{M}-\mathrm{E}$ average & -0.6 & -0.3 & 0.0 & -0.3 \\
\hline $\mathrm{M}-\mathrm{E} \mathrm{SD}$ & 0.3 & 0.3 & 0.3 & 0.4 \\
\hline \multicolumn{5}{|c|}{ Curd firmness $\left(\mathrm{a}_{30}\right), \mathrm{mm}$} \\
\hline Observations, $\mathrm{n}$ & 30 & 52 & 19 & 101 \\
\hline Measured (M) & 36.3 & 28.5 & 15.5 & 28.4 \\
\hline Estimated (E) & 36.9 & 28.2 & 14.3 & 28.1 \\
\hline $\mathrm{M}-\mathrm{E}$ average & -0.6 & 0.3 & 1.2 & 0.2 \\
\hline $\mathrm{M}-\mathrm{E} \mathrm{SD}$ & 0.7 & 0.3 & 0.4 & 0.8 \\
\hline \multicolumn{5}{|c|}{ Curd-firming time $\left(\mathrm{k}_{20}\right)$, min } \\
\hline Observations, $\mathrm{n}$ & 29 & 45 & 5 & 79 \\
\hline Measured (M) & 3.8 & 5.5 & 5.3 & 4.9 \\
\hline Estimated (E) & 3.8 & 5.8 & 5.8 & 5.1 \\
\hline $\mathrm{M}-\mathrm{E}$ average & 0.1 & -0.3 & -0.5 & -0.2 \\
\hline $\mathrm{M}-\mathrm{E} \mathrm{SD}$ & 0.3 & 0.2 & 0.3 & 0.3 \\
\hline
\end{tabular}

${ }^{1}$ By Foss Electric A/S (Hillerød, Denmark).

${ }^{2} \mathrm{M}=$ measured directly by computerized renneting meters (point measurement); $\mathrm{E}=$ estimated by means of the $C F_{t}$ individual equations (based on all observations of the sample).

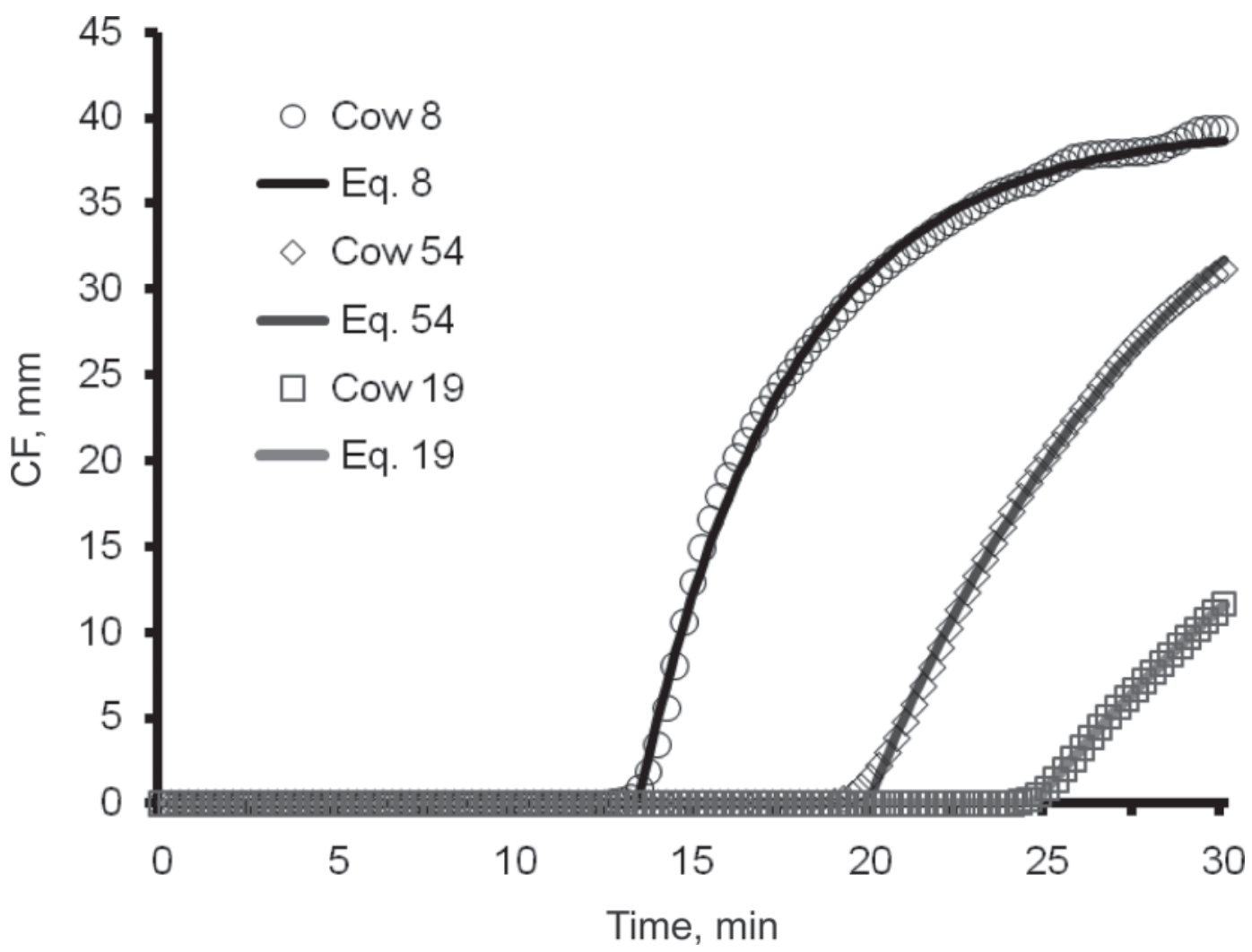

Figure 2. Individual observations and curd firmness $(\mathrm{CF})$ at time $t\left(C F_{t}\right)$ equations (Eq.) obtained from milk samples characterized by fast [cow no. 8: rennet coagulation time $(\mathrm{RCT}), 13.4 \mathrm{~min}$; asymptotical potential value of $\mathrm{CF}$ at an infinite time $\left(\mathrm{CF}_{\mathrm{P}}\right), 39.5 \mathrm{~mm}$; curd-firming rate constant $\left(\mathrm{k}_{\mathrm{CF}}\right), 23.3 \% \times \mathrm{min}^{-1}$ ], average (cow no. 54: $\mathrm{RCT}, 19.9 \mathrm{~min} ; \mathrm{CF}_{\mathrm{P}}, 48.5 \mathrm{~mm} ; \mathrm{k}_{\mathrm{CF}}, 10.5 \% \times \min ^{-1}$ ), and slow coagulation $($ cow no. 19 : $\left.\mathrm{RCT}, 24.6 \mathrm{~min} ; \mathrm{CF}_{\mathrm{P}}, 48.1 \mathrm{~mm} ; \mathrm{k}_{\mathrm{CF}}, 5.2 \% \times \mathrm{min}^{-1}\right)$. 
Table 4. Descriptive statistics of curd-firming time $\left(\mathrm{k}_{20}\right)$ values estimated by curd firmness at time $t\left(C F_{t}\right)$ equations grouped according to their direct measurability or not by a Formagraph ${ }^{1}$ (trial 1: individual samples)

\begin{tabular}{lccccc}
\hline Item $^{2}$ & $\mathrm{n}$ & Mean & SD & Minimum & Maximum \\
\hline $\mathrm{k}_{20}$ measurable by Formagraph & 79 & 5.1 & 1.6 & 1.4 & 8.2 \\
$\mathrm{k}_{20}$ not measurable by Formagraph & 22 & - & - & - & - \\
Convergent equations & 10 & 10.5 & 2.0 & 8.7 & 14.1 \\
Nonconvergent equations & 10 & 8.4 & 1.9 & 6.1 & 11.7 \\
Not estimable $\left(\mathrm{CF}_{\mathrm{P}}<20 \mathrm{~mm}\right)$ & 2 & - & - & - & - \\
\hline
\end{tabular}

${ }^{1}$ By Foss Electric A/S (Hillerød, Denmark).

${ }^{2} \mathrm{CF}_{\mathrm{P}}=$ potential asymptotical curd firmness.

Of the 101 coagulating samples, 22 did not attain a $\mathrm{CF}$ of at least $20 \mathrm{~mm}$ at the end of the trial $\left(\mathrm{a}_{30}<20\right.$ $\mathrm{mm}$ ), so that the $\mathrm{k}_{20}$ values could not be measured by the instrument. The difference between measured and estimated $\mathrm{k}_{20}$ values was, on average, low, and of limited variability $(-0.2 \pm 0.3 \mathrm{~min})$, even if the estimates were somewhat higher than the measured data when slowly coagulating samples were tested (Table 3 ).

The adoption of the $C F_{t}$ model allowed the estimation of $\mathrm{k}_{20}$, even for samples characterized by $\mathrm{a}_{30}<20$ $\mathrm{mm}$, provided that $C F_{P}>20 \mathrm{~mm}$. Of the 22 samples with $\mathrm{a}_{30}<20 \mathrm{~mm}$, only 2 had $C F_{P}<20 \mathrm{~mm}$ and thus, $\mathrm{k}_{20}$ cannot be estimated. Ten of the 20 samples with $\mathrm{a}_{30}<20 \mathrm{~mm}$ and $C F_{P}>20 \mathrm{~mm}$ were characterized by convergent equations. Their $\mathrm{k}_{20}$ average value was more than 2 -fold the average of the 79 samples measurable directly by the Formagraph (Table 4 ), but their variability was similar. The last 10 samples were characterized by nonconvergent equations; nevertheless, $\mathrm{k}_{20}$ was estimated and the average value was intermediate between the other 2 groups of samples (Table 4).

The data of Table 5 reveal the strong similarity of the measured and estimated values, both for RCT and $\mathrm{a}_{30}$; the coefficient of determination values are very high (0.996 and 0.997 respectively), the RSD are very low $(0.27 \mathrm{~min}$ and $0.54 \mathrm{~mm})$, and also the intercepts are very low $(-1.5 \mathrm{~min}$ and $+1.8 \mathrm{~mm})$. Moreover, regressions forced to have zero intercepts show coefficients of determination higher than 0.99 , RSD very low, and regression coefficients very close to unity. Also, with the $\mathrm{k}_{20}$ data, the coefficients of determination between measured and estimated values were high, but slightly lower than those for RCT and $\mathrm{a}_{30}$ (0.972 for a linear regression with a free intercept and 0.958 for a regression forced to the origin). Again, the between-value ratio, being 0.959 , is acceptable, particularly if the degree of difficulty associated with estimation of the parameter is considered and if the low RSD is considered.

Figure 3 confirms the dependency of $\mathrm{a}_{30}$ on RCT, especially for slowly coagulating samples. Figure 4 shows, on the contrary, that the asymptotic parameter $C F_{P}$ is practically independent of RCT, whereas Figure 5 reveals that $C F_{P}$ is also independent of $a_{30}$. Lastly, Figure 6 shows that, as expected, the $k_{C F}$ parameter of the model and the traditional $\mathrm{k}_{20}$ measures are correlated, but certainly do not represent the same value. So, Figures 4, 5, and 6 confirm that the model, through its parameters, is able to capture and express information on the curd firming process not included in the traditional MCP traits.

\section{Trial 2: Repeatability of MCP}

Compared with the individual Brown Swiss milk samples of trial 1, the bulk milk from Holstein-Friesian cows used in the repeatability trial (trial 2) had lower

Table 5. Linear regression ${ }^{1}$ between milk coagulation properties (MCP) measured by a Formagraph ${ }^{2}$ or estimated by curd firmness at time $t\left(C F_{t}\right)$ equations (trial 1: individual samples)

\begin{tabular}{lrrrrr}
\hline Item & $\mathrm{n}$ & $\mathrm{a}$ & $\mathrm{b}$ & $\mathrm{RSD}$ & $\mathrm{R}^{2}$ \\
\hline $\begin{array}{l}\text { Rennet coagulation time (RCT) } \\
\text { Linear regression }\end{array}$ & 101 & -1.5 & 1.061 & 0.27 & 0.996 \\
$\quad$ Ratio & 101 & 0.0 & 0.984 & 0.40 & 0.991 \\
$\quad$ Curd firmness ( $\left.\mathrm{a}_{30}\right)$ & & & & & \\
$\quad$ Linear regression & 101 & 1.8 & 0.946 & 0.54 & 0.997 \\
$\quad$ Ratio & 101 & 0.0 & 1.001 & 0.82 & 0.993 \\
$\quad$ Curd-firming time $\left(\mathrm{k}_{20}\right)$ & 87 & 0.5 & 0.862 & 0.24 & 0.972 \\
$\quad$ Linear regression & 87 & 0.0 & 0.959 & 0.29 & 0.958 \\
$\quad$ Ratio & 87 \\
\hline
\end{tabular}

${ }^{1} \mathrm{a}=$ intercept $\mathrm{b}=$ slope; $\mathrm{RSD}=$ residual standard deviation.

${ }^{2}$ By Foss Electric A/S (Hillerød, Denmark).

${ }^{3}$ Ratio, linear regression forced to pass through origin. 


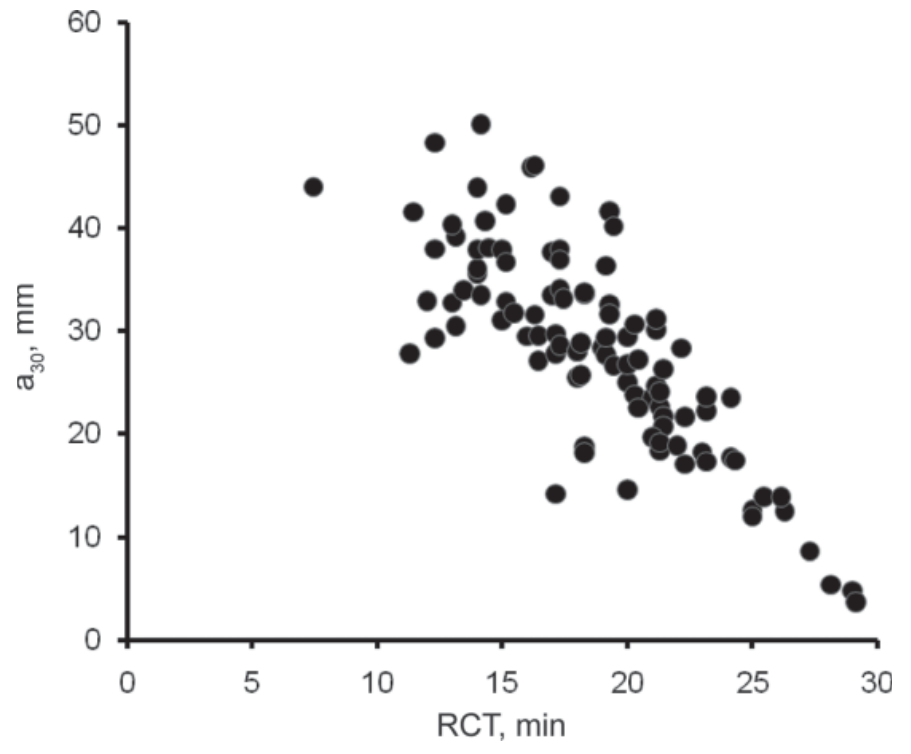

Figure 3. Relationship between measured curd firmness $\left(\mathrm{a}_{30}\right)$ and measured rennet coagulation time $\left(\mathrm{RCT} ; \mathrm{a}_{30}=63.4-1.876 \times \mathrm{RCT}\right.$ $\left.\mathrm{n}=101 ; \mathrm{R}^{2}=0.65\right)$.

contents of fat, protein, and $\mathrm{CN}$, and reduced acidity (Table 1). Moreover, repeated analyses showed, as expected, a much lower variability compared with that of the individual samples of trial 1 . However, repeatability was much more reliable in terms of protein, $\mathrm{CN}$, and lactose content than for fat level and acidity (Table 1).

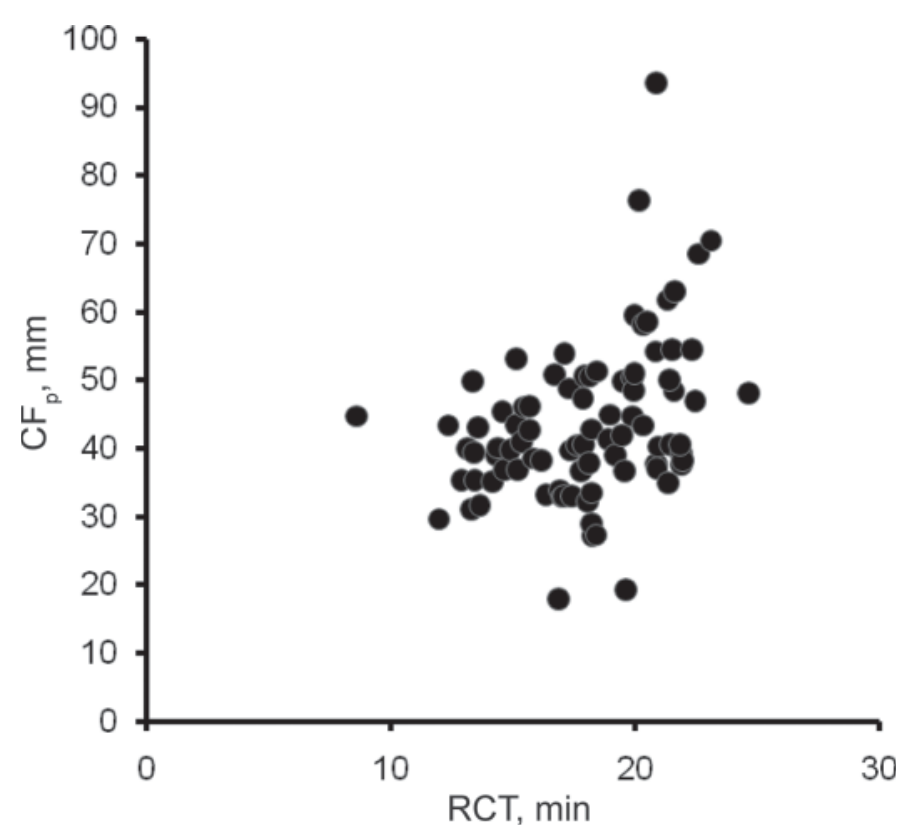

Figure 4. Relationship between estimated potential asymptotical curd firmness $\left(\mathrm{CF}_{\mathrm{P}}\right)$ and estimated rennet coagulation time (RCT; $\left.\mathrm{CF}_{\mathrm{P}}=18.9+1.37 \times \mathrm{RCT} ; \mathrm{n}=87 ; \mathrm{R}^{2}=0.14\right)$.

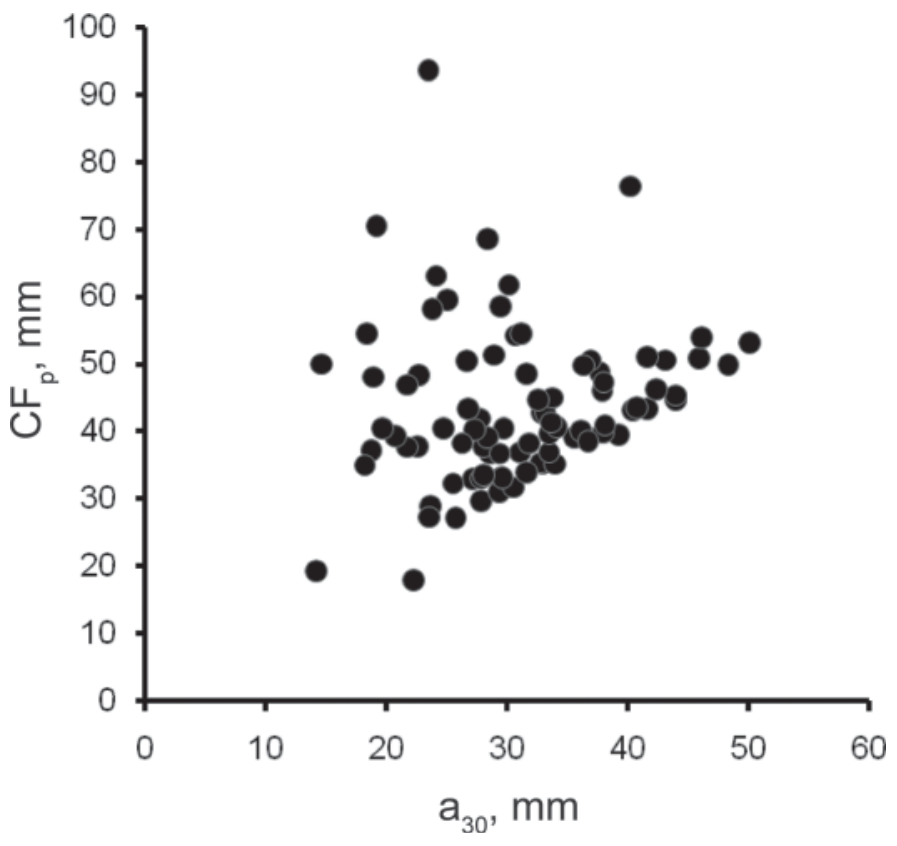

Figure 5. Relationship between estimated potential asymptotical curd firmness $\left(\mathrm{CF}_{\mathrm{P}}\right)$ and measured curd firmness $\left(\mathrm{a}_{30} ; \mathrm{CF}_{\mathrm{P}}=37.1+\right.$ $\left.0.213 \times \mathrm{a}_{30} ; \mathrm{n}=101 ; \mathrm{R}^{2}=0.02\right)$.

Even though all analyses were performed on the same bulk milk from Monday morning milking of 5 cows $(2$ samples analyzed per day $\times 5$ consecutive days $\times 5$ replicates $=50$ observations), the data file for 1 replicate was not available, the equation for 1 replicate did not converge, and the equation for another replicate was considered to be an outlier and was excluded. Thus, data from 47 equations were used to analyze sources of variation.

The equation fit was very good; the average of the 47 RSD was only $0.13 \mathrm{~mm}$, with a standard deviation of $0.03 \mathrm{~mm}$ (Table 6), and the coefficients of determination of individual equations were all higher than 0.999 (data not shown). Also, the variability of the estimated parameters used to form $C F_{t}$ equations for the replicates of trial 2 was, as expected, much lower than that of the individual equations of trial 1 (Table 6 ).

Analysis of variance showed that the day of analysis significantly affected both RCT and $C F_{P}$, but not $k_{C F}$, and not the standard error of parameter estimates. On the contrary, the within-day sample effect was never significant (Table 6). Repeatability of RCT was very good, and the novel parameters of the $C F_{t}$ equations were less reliable, even if the individual equations showed a very good fit.

Turning to traditional MCP parameters (Table 7), it was again evident that the day of analysis significantly affected all such values, whereas the within-day sample effect was minimal. In all instances, estimated 


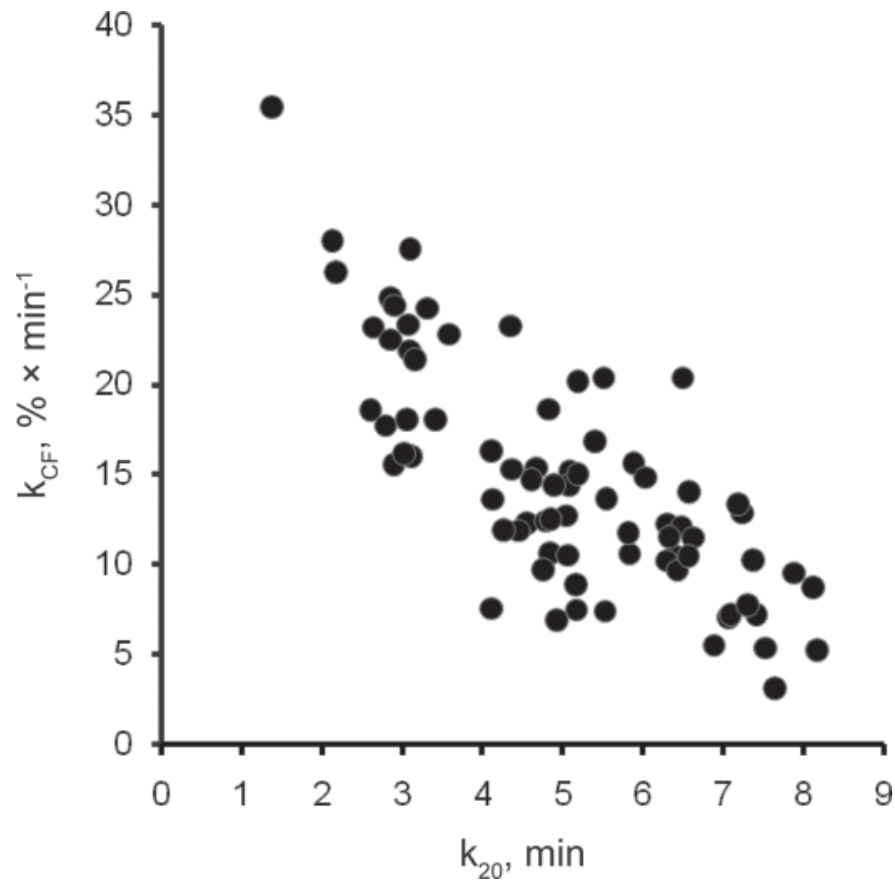

Figure 6. Relationship between estimated curd firming rate $\left(\mathrm{k}_{\mathrm{CF}}\right)$ and measured curd firming time $\left(\mathrm{k}_{20}\right)\left(\mathrm{k}_{\mathrm{CF}}=29.4-2.93 \times \mathrm{k}_{20} ; \mathrm{n}=\right.$ $\left.87 ; \mathrm{R}^{2}=0.59\right)$.

parameter repeatability based on individual $C F_{t}$ equation data was slightly better than when traditionally calculated figures were derived.

\section{DISCUSSION}

\section{Measured and Estimated MCP}

The higher nutrient contents of milk samples from Brown Swiss cows (used in trial 1), compared with bulk milk samples from the Holstein-Friesian cows of trial 2, are in line with the reported milk quality characteris- tics of the 2 breeds obtained from larger data sets (De Marchi et al., 2007). Also, the average MCP values of the individual milk samples confirm the superiority of the alpine breed, although the values were somewhat less favorable than reported earlier (Mariani et al., 1984; Cecchinato et al., 2011). The 4 noncoagulating samples among the 105 samples analyzed represents a proportion normal for Brown Swiss cows; Cecchinato et al. (2011) found that 3.5\% of samples from 1,234 individually analyzed Brown Swiss cows were noncoagulating (by comparison, $9.7 \%$ of 1,025 HolsteinFriesian samples were noncoagulating). Moreover, of a total of 101 coagulating samples, 22 failed to reach an oscillation interval of at least $20 \mathrm{~mm}$ within $30 \mathrm{~min}$ of rennet addition and $\mathrm{k}_{20}$ values, thus, could not be measured by the instrument. This proportion of latecoagulating samples can be viewed as normal when milk from Brown Swiss cows is analyzed. De Marchi et al. (2007) studied milk from 5 breeds and found that $16 \%$ of 153 bulk milk samples from Brown Swiss herds failed to yield a $\mathrm{k}_{20}$ parameter. In comparison, when 83 bulk milk samples from Holstein-Friesian herds were analyzed, the proportion failing to attain $20-\mathrm{mm}$ oscillation within 30 min was $59 \%$.

Taking into consideration that $\mathrm{k}_{20}$ is used as an estimation of the time needed between coagulation and the cutting of curd, it is a paradox that $\mathrm{k}_{20}$ is lacking for the samples that are more problematic for processing and that need this information more than others. The adoption of $C F_{t}$ modeling allows removal of this limitation, as the equations can be used to estimate $\mathrm{CF}$ trend beyond the end of the test (thirtieth minute). Of the 101 coagulating samples, only 2 were characterized by $C F_{P}<20 \mathrm{~mm}$, so that $\mathrm{k}_{20}$ could not be estimated (1 fast and 1 average-coagulating sample).

The results of both trials showed that the new model offers a very good fit to the many CF observations recorded by CRM devices for all coagulating milk

Table 6. Analysis of variance and repeatability (RP) of estimated parameters of curd firmness at time $t\left(C F_{t}\right)$ equations (trial 2: 47 bulk milk replicates $)^{1}$

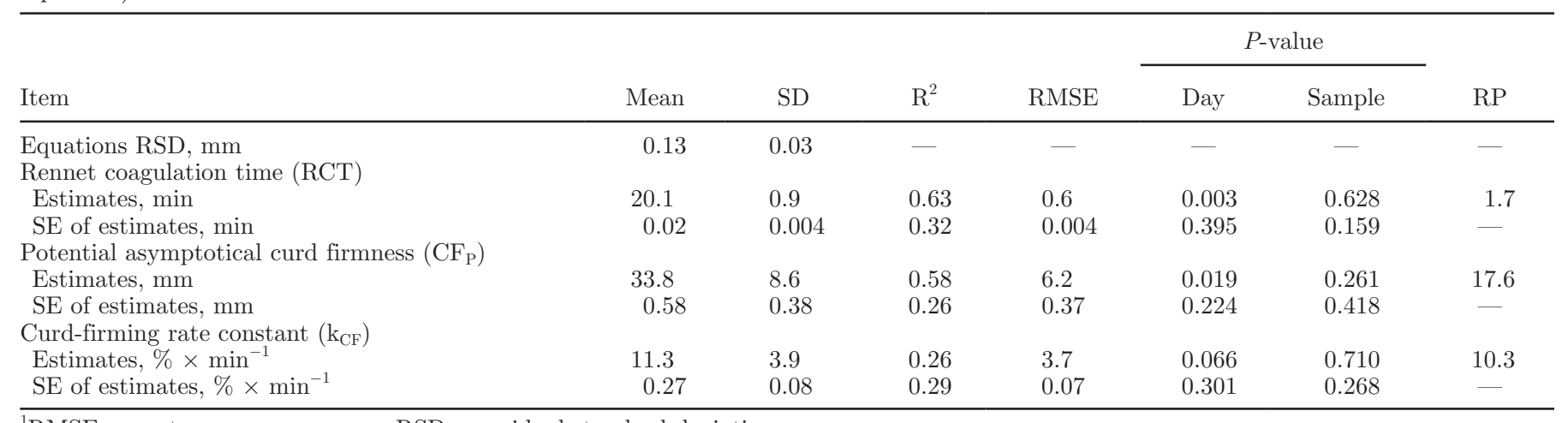

${ }^{1} \mathrm{RMSE}=$ root mean square error; $\mathrm{RSD}=$ residual standard deviation. 
Table 7. Analysis of variance and repeatability (RP) of milk coagulation properties (MCP) measured or estimated by curd firmness at time $t$ $\left(C F_{t}\right)$ equations (trial 2: 47 bulk milk replicates) ${ }^{1}$

\begin{tabular}{|c|c|c|c|c|c|c|c|}
\hline Item & Mean & SD & $\mathrm{R}^{2}$ & RMSE & \multicolumn{2}{|c|}{$P$-value } & $\mathrm{RP}$ \\
\hline Estimated (E) & 20.11 & 0.88 & 0.63 & 0.60 & 0.003 & 0.628 & 1.6 \\
\hline $\mathrm{M}-\mathrm{E}$ & -0.18 & 0.18 & 0.22 & 0.18 & 0.343 & 0.461 & \\
\hline \multicolumn{8}{|c|}{ Curd firmness $\left(\mathrm{a}_{30} ; \mathrm{n}=47\right), \mathrm{mm}$} \\
\hline$M-E$ & 0.22 & 0.39 & 0.43 & 0.33 & 0.002 & 0.935 & \\
\hline \multicolumn{8}{|c|}{ Curd-firming time $\left(\mathrm{k}_{20} ; \mathrm{n}=29\right)$, min } \\
\hline Measured (M) & 7.74 & 1.38 & 0.69 & 0.90 & 0.022 & 0.404 & 2.6 \\
\hline Estimated (E) & 8.18 & 1.36 & 0.70 & 0.88 & 0.010 & 0.601 & 2.4 \\
\hline$M-E$ & -0.44 & 0.21 & 0.31 & 0.21 & 0.946 & 0.117 & \\
\hline
\end{tabular}

${ }^{1} \mathrm{RMSE}=$ root mean square error; $\mathrm{M}=$ measured directly by computerized renneting meters (point measurement); $\mathrm{E}=$ estimated by means of the $C F_{t}$ individual equations (based on all observations of the sample).

samples; this was true even when the equations did not meet the convergence criterion. The $C F_{t}$ model equations for coagulating samples allowed estimation of traditional MCP values (RCT, $\mathrm{a}_{30}$, and $\mathrm{k}_{20}$ ), using all available information, thus not relying on conventional single-point data. However, the newly estimated MCP values were very similar to those directly measured by CRM equipment. The traditional parameters are useful not only to the industry, but (in some instances) are employed to trigger premium payments, especially when Protected Designation of Origin hard cheeses are to be made. Moreover, MCP values are heritable, both as measured directly (Ikonen et al., 1999, 2004; Cassandro et al., 2008; Vallas et al., 2010; Cecchinato et al., 2011) and when estimated indirectly from the MIRS spectra of unprocessed milk (Cecchinato et al., 2009). Moreover, the MCP are strongly influenced by the genotypes of $\mathrm{CN}$ and whey proteins (Boettcher et al., 2004; Comin et al., 2005, 2008; Kübarsepp et al., 2005b; Hallén et al., 2007; Tyrisevä et al., 2008; Penasa et al., 2010).

The repeatability of RCT and $\mathrm{a}_{30}$ estimates was very good; indeed slightly better than that found on the same breed by Dal Zotto et al. (2008), whereas the data are not comparable with those of Caroli et al. (1990), because the methodologies differed. In terms of $\mathrm{k}_{20}$, no repeatability data are available. The repeatability of estimated MCP values was slightly better than was that of traditional measurements.

The reliability of MCP values estimated using $C F_{t}$ equations should be tested in future work that should also compare the heritability of estimated and measured MCP values and genetic correlations thereof, considering that MCP values estimated indirectly by MIRS are more heritable than are the measured values (Cecchinato et al., 2009).
Use of the $C F_{t}$ model can help to solve the problem of the increasing frequency of slowly coagulating milk samples, as the $k_{20}$ value can be estimated even if the sum of the RCT and $k_{20}$ is $>30$ min. The 10 samples with $\mathrm{a}_{30}<20 \mathrm{~mm}$, but with convergent equations, were average- (6 samples) or slowly coagulating (4 samples) milk samples characterized by different $C F_{P}(52.2 \pm$ $30.2 \mathrm{~mm})$, always with low $k_{C F}$ values $(6.3 \pm 2.4 \%)$. This last parameter explains why the estimated $k_{20}$ of these samples is, on average, more than 2 -fold the average of the others, so that coagulation can be normal but the curd firming rate is very slow.

The 10 samples with $\mathrm{a}_{30}<20 \mathrm{~mm}$, but with nonconvergent equations, on the contrary, were all very slowly coagulating $(\mathrm{RCT}=26.5 \pm 11.8 \mathrm{~min})$. The small number of observations available until the end of the test (thirtieth minute) does not allow a correct estimation of $C F_{P}$ and $k_{C F}$ parameters. Especially in this case, it can be questioned if it is correct to use these equations and to extend them beyond the observation field. Some justification is that the coefficients of determination of these equations are always $>0.99$ and that the extension beyond the end of the test is limited because the sum of RCT and $\mathrm{k}_{20}$ is equal to $31.9 \pm 1.4$ min for the 10 samples with convergent equations and to $34.8 \pm 3.1 \mathrm{~min}$ for nonconvergent ones. In addition, noncoagulating milk samples can be reliably assessed if test duration is increased; the model permits prolonged observation.

\section{New Parameters Describing Coagulation and Curd Firming}

The intrinsic limits of traditional MCP values and the increase in the frequency of noncoagulating and slowly coagulating milk evidence the need for new pa- 
rameters and changes in test conditions. Asymptotical potential curd firmness and $k_{C F}$ can be precisely estimated for all coagulating samples excepting those that coagulate very late. Although the $C F_{t}$ equations for late-coagulating samples fit the data very well, observations with a $C F_{t}>0 \mathrm{~mm}$ were too few to permit precise contemporaneous estimation of both $C F_{P}$ and $k_{C F}$. The $C F_{t}$ model does not accurately describe the curd-firming process of late-coagulating samples unless trial duration is prolonged.

The repeatability values of both parameters were quite low but, again, this is not attributable to the model, but rather to the intrinsic repeatability of the analytical technique and, for late-coagulating samples, to the low amount of useful information.

The $C F_{P}$ parameter is not dependent on either RCT or $\mathrm{a}_{30}$, and, thus, contributes additional information on coagulation and CF. Also, the $k_{C F}$ parameter is not strictly correlated with other values. On average, milk samples that begin to coagulate early are characterized by a $C F_{P}$ that tends to be lower than average but also by a rapid rise toward the asymptotic value (Figure 2). The opposite is true for slowly coagulating samples; the firmness is potentially higher but the $C F_{t}$ rise is slower.

\section{CONCLUSIONS}

In conclusion, all information gathered over $30 \mathrm{~min}$ of computer-monitored renneting can be interpreted using a simple model that explains almost all $C F_{t}$ variability in any individual coagulating sample. The model uses only 3 parameters: the RCT, the $k_{C F}$, and the $C F_{P}$. These embrace all available information. The model offers a very good fit of data obtained from milk samples very different in composition, produced by cows of different breeds, ages, DIM, and reared on different farms. Samples showing very late coagulation yielded very few observations; it was, thus, difficult to estimate curve parameters. The repeatability values of the parameters reflect the reliability of the technique; such value was better for RCT than for the other 2 parameters. Also, other traditional traits $\left(\mathrm{a}_{30}\right.$ and $\left.\mathrm{k}_{20}\right)$ can be estimated using the individual equations derived for all coagulating samples, again using all available information. The values of traditional parameters estimated from individual equations were very close to the single-point measures yielded by the instrument, but repeatability was slightly better. Moreover, $\mathrm{k}_{20}$ can be estimated also for samples with very late coagulation time or with very slow curd-firming rate. Lastly, the novel parameters yielded by use of individual equations are more independent than are those of the traditional MCP. The practical and scientific utility of the $C F_{P}$ and $k_{C F}$ parameters should be further investigated from both phenotypic and genetic viewpoints.

\section{ACKNOWLEDGMENTS}

The author thanks Barbara Contiero, Alessio Cecchinato, Massimo De Marchi, Mauro Penasa, and Claudio Cipolat Gotet of the Department of Animal Science of the University of Padova (Italy) for valuable cooperation and advice. Also, the author thanks the Autonomous Province of Trento (Italy) for funding the project.

\section{REFERENCES}

Aleandri, R., J. C. Schneider, and L. G. Buttazzoni. 1989. Evaluation of milk for cheese production based on milk characteristics and Formagraph measures. J. Dairy Sci. 72:1967-1975.

Annibaldi, S., G. Ferri, and R. Mora. 1977. Nuovi orientamenti nella valutazione tecnica del latte: Tipizzazione lattodinamografica. Sci. Tecn. Latt. Cas. 28:115-126.

Boettcher, P. J., A. Caroli, A. Stella, S. Chessa, E. Budelli, F. Canavesi, S. Ghiroldi, and G. Pagnacco. 2004. Effects of casein haplotypes on milk production traits in Italian Holstein and Brown Swiss cattle. J. Dairy Sci. 87:4311-4317.

Bynum, D. G., and N. F. Olson. 1982. Influence of curd firmness at cutting on Cheddar cheese yield and recovery of milk constituents. J. Dairy Sci. 65:2281-2290.

Caroli, A., P. Bolla, G. Pagnacco, M. Rampilli, and L. Degano. 1990. Repeatability of milk clotting aptitude evaluated by lactodynamographic analysis. J. Dairy Res. 57:141-142.

Cassandro, M., A. Comin, M. Ojala, R. Dal Zotto, M. De Marchi, L. Gallo, P. Carnier, and G. Bittante. 2008. Genetic parameters of milk coagulation properties and their relationships with milk yield and quality traits in Italian Holstein cows. J. Dairy Sci. 91:371-376.

Cecchinato, A., and P. Carnier. 2011. Short communication: Statistical models for the analysis of coagulation traits using coagulating and non-coagulating milk information. J. Dairy Sci. 94:4214-4219.

Cecchinato, A., M. De Marchi, L. Gallo, G. Bittante, and P. Carnier. 2009. Mid-infrared spectroscopy predictions as indicator traits in breeding programs for enhanced coagulation properties of milk. J. Dairy Sci. 92:5304-5313.

Cecchinato, A., M. Penasa, M. De Marchi, L. Gallo, G. Bittante, and P. Carnier. 2011. Genetic parameters of coagulation properties, milk yield, quality, and acidity estimated using coagulating and non-coagulating milk information in Brown Swiss and HolsteinFriesian cows. J. Dairy Sci. 94:4205-4213.

Comin, A., M. Cassandro, S. Chessa, M. Ojala, R. Dal Zotto, M. De Marchi, P. Carnier, L. Gallo, G. Pagnacco, and G. Bittante. 2008. Effects of $\beta$ - and $\kappa$-casein genotypes on milk coagulation, quality, and yield traits in Italian Holstein cows. J. Dairy Sci. 91:4022-4027.

Comin, A., M. Cassandro, M. Povinelli, and G. Bittante. 2005. Genetic aspects of milk coagulation properties in Italian Holstein cows. Ital. J. Anim. Sci. 4(Suppl. 2):10-12.

Dal Zotto, R., M. De Marchi, A. Cecchinato, M. Penasa, M. Cassandro, P. Carnier, L. Gallo, and G. Bittante. 2008. Reproducibility and repeatability of measures of milk coagulation properties and predictive ability of mid-infrared reflectance spectroscopy. J. Dairy Sci. 91:4103-4112.

De Marchi, M., G. Bittante, R. Dal Zotto, C. Dalvit, and M. Cassandro. 2008. Effect of Holstein Friesian and Brown Swiss breeds on quality of milk and cheese. J. Dairy Sci. 91:4092-4102.

De Marchi, M., R. Dal Zotto, M. Cassandro, and G. Bittante. 2007. Milk coagulation ability of five dairy cattle breeds. J. Dairy Sci. 90:3986-3992. 
De Marchi, M., C. C. Fagan, C. P. O’Donnell, A. Cecchinato, R. Dal Zotto, M. Cassandro, M. Penasa, and G. Bittante. 2009. Prediction of coagulation properties, titratable acidity, and $\mathrm{pH}$ of bovine milk using mid-infrared spectroscopy. J. Dairy Sci. 92:423-432.

Dejmek, P. 1987. Dynamic rheology of rennet curd. J. Dairy Sci. 70:1325-1330.

Douillard, R. 1973. Rheological analysis of curd formation. J. Texture Stud. 4:158-165

Douillard, R. 1986. A kinetic-model for protease-induced milk clotting and curdling. Lebenson. Wiss. Technol. 19:202-207.

Fagan, C. C., M. Castillo, F. A. Payne, C. P. O'Donnell, M. Leedy, and D. J. O'Callaghan. 2007. Novel technology for continuous monitoring of milk coagulation and whey separation in cheesemaking. J. Agric. Food Chem. 55:8836-8844.

Gervais, A., and O. Cerf. 1983. Comparison of two models for fitting rennet-induced milk coagulation kinetics. J. Texture Stud. 14:47-59.

Hallén, E., T. Allmere, J. Näslund, A. Andrén, and A. Lundén. 2007. Effect of genetic polymorphism of milk proteins on rheology of chymosin-induced milk gels. Int. Dairy J. 17:791-799.

Ikonen, T., K. Ahlfors, R. Kempe, M. Ojala, and O. Ruottinen. 1999. Genetic parameters for the milk coagulation properties and prevalence of noncoagulating milk in Finnish dairy cows. J. Dairy Sci. 82:205-214.

Ikonen, T., S. Morri, A.-M. Tyrisevä, O. Ruottinen, and M. Ojala. 2004. Genetic and phenotypic correlations between milk coagulation properties, milk production traits, somatic cell count, casein content, and pH of milk. J. Dairy Sci. 87:458-467.

ISO (International Organization for Standardization). 1994a. Accuracy (trueness and precision) of measurement methods and resultsPart 1: General principles and definitions. ISO 5725-1. International Organization for Standardization, Geneva, Switzerland.

ISO (International Organization for Standardization). 1994b. Accuracy (trueness and precision) of measurement methods and results-Part 2: Basic method for the determination of repeatability and reproducibility of a standard measurement method. ISO 5725-2. International Organization for Standardization, Geneva, Switzerland.

Klandar, A. H., A. Lagaude, and D. Chevalier-Lucia. 2007. Assessment of the rennet coagulation of skim milk: A comparison of methods. Int. Dairy J. 17:1151-1160.

Kübarsepp, I., M. Henno, O. Kärt, and T. Tupasela. 2005a. A comparison of the methods for determination of the rennet coagulation properties of milk. Acta Agric. Scand. A Anim. Sci. 55:145-148.

Kübarsepp, I., M. Henno, H. Viinalass, and D. Sabre. 2005b. Effect of $\kappa$-casein and $\beta$-lactoglobulin genotypes on the milk rennet coagulation properties. Agron. Res. 3:55-64.

Mariani, P., M. Pecorari, and E. Fossa. 1984. Le caratteristiche di coagulazione del latte delle razze Bruna e Frisona nella produzi- one del formaggio parmigiano-reggiano. Pages 319-327 in Atti del XVI Congresso Nazionale della Società Italiana di Buiatria. SIB, Modena, Italy.

Martin, B., J.-F. Chamba, J.-B. Coulon, and E. Perreard. 1997. Effect of milk chemical composition and clotting characteristics on chemical and sensory properties of Reblochon de Savoie cheese. J. Dairy Res. 64:157-162.

McMahon, D. J., and R. J. Brown. 1982. Evaluation of Formagraph for comparing rennet solutions. J. Dairy Sci. 65:1639-1642.

McMahon, D. J., G. H. Richardson, and R. J. Brown. 1984. Enzymic milk coagulation: Role of equations involving coagulation time and curd firmness in describing coagulation. J. Dairy Sci. 67:11851193.

O'Callaghan, D. J., and T. P. Guinee. 1996. Comparison of mathematical models applied to rennet coagulation of skim milks. J. Texture Stud. 26:607-633.

O'Callaghan, D. J., C. P. O'Donnell, and F. A. Payne. 2002. Review of systems for monitoring curd setting during cheesemaking. Int. J. Dairy Technol. 55:65-74.

Okigbo, L. M., G. H. Richardson, R. J. Brown, and C. A. Ernstrom. 1985. Variation in coagulation properties of milk from individual cows. J. Dairy Sci. 68:822-828.

Penasa, M., M. Cassandro, D. Pretto, M. De Marchi, A. Comin, S. Chessa, R. Dal Zotto, and G. Bittante. 2010. Short communication: Influence of composite casein genotypes on additive variation of milk production traits and coagulation properties in HolsteinFriesian cows. J. Dairy Sci. 93:3346-3349.

SAS Institute. 2001. SAS User's Guide: Statistics. Release 8.2. SAS Institute Inc., Cary, NC.

Tyrisevä, A.-M., K. Elo, A. Kuusipuro, V. Vilva, I. Jänönen, H. Karjalainen, T. Ikonen, and M. Ojala. 2008. Chromosomal regions underlying noncoagulation of milk in Finnish Ayrshire cows. Genetics 180:1211-1220.

Tyrisevä, A. M., T. Vahlsten, O. Ruottinen, and M. Ojala. 2004 Noncoagulation of milk in Finnish Ayrshire and Holstein-Friesian cows and effect of herds on milk coagulation ability. J. Dairy Sci 87:3958-3966

Vallas, M., H. Bovenhuis, T. Kaart, K. Pärna, H. Kiiman, and E. Pärna. 2010. Genetic parameters for milk coagulation properties in Estonian Holstein cows. J. Dairy Sci. 93:3789-3796.

Wedholm, A., L. B. Larsen, H. Lindmark-Månsson, A. H. Karlsson, and A. Andrén. 2006. Effect of protein composition on the cheesemaking properties of milk from individual dairy cows. J. Dairy Sci. 89:3296-3305.

Zannoni, M., and S. Annibaldi. 1981. Standardization of the renneting ability of milk by Formagraph. Sci. Tecn. Latt. Cas. 32:79-94. 